\title{
Volatile organic compounds in normal human exhaled breath: a long neglected pollutant source
}

\author{
X. Sun \& X. Yang \\ Department of Building Science, Tsinghua University, Beijing, PR China
}

\begin{abstract}
At present, indoor VOCs pollution has widespread concern. However, for human emission of VOCs, fundamental data was in shortage in the field of indoor air quality (IAQ). In this study, 11 male subjects without a smoking habit, 12 female subjects without a smoking habit and 12 male subjects with a smoking habit were selected. Their samples of exhaled breath were collected and concentrated by sampling bags and sorbent tubes, and analyzed by gas chromatography-mass spectrometry (GC/MS). 135 VOCs were observed in all 35 samples. An average breath sample contained 79.7 VOCs (SD16.2, range 43-110) were obtained, 12 VOCs were observed in all 35 subjects. Furthermore, quantitative analysis of main indoor pollutants: benzene, toluene, xylene and naphthalene were performed, as well as TVOC. The effect of gender was found to be not as strong a factor as the effect of the smoking habit. Exhaled VOCs of female subjects were of higher concentration than those of male subjects. Exhaled VOCs of subjects with a smoking habit were more diverse and of higher concentration.
\end{abstract}

Keywords: volatile organic compounds, exhaled breath, indoor air quality.

\section{Introduction}

Indoor air pollutions are gaining increasing prominence as a public health problem. Concerns about potential public health problems due to indoor air pollution are based on evidence that urban residents typically spend more than 90 percent of their time indoors; concentrations of some contaminants are higher indoors than outdoors, such as volatile organic compounds (VOCs) [1]. VOCs constitute an important class of indoor-air contaminants. Building materials and interior furnishings produce a surprising array of VOC emissions, which was concerned to cause both acute and chronic human health effects, even at low levels [2]. Evidence from a variety of non-industrial building investigations and systematic 
studies found that $60 \%$ of the VOCs indoors come from building materials and furnishings [3]. Human emanation, which also plays a role in indoor air quality (IAQ), is short of systematic theory and fundamental data. Researchers have proposed 'olf' to describe the emission rate of air pollutants (bioeffluents) from a standard person or any other pollution source causing the same dissatisfaction as one standard person does, is a relative concept [4]. However, neither the kinds of pollutant nor the content were studied quantitatively. Human emanation needs to be taken into consideration especially in crowded environment.

In the 1970s, it was found that human could emit VOCs. The source of VOCs was mainly brought in by breath and synthesis, and the emission of VOCs was composed mainly by metabolism, excretion and exhalation. The progress of medically breath analysis was in correlation with the enormous progress in trace gas analytical techniques [5]. Researchers have detected hundreds of volatile organic compounds in exhaled air, and in part they were with relation to illness. Dimethyl sulfide, acetone, 2-butanone and 2-pentanone were increased in the breath of liver patients [6], and the VOCs of 1-butanol and 3-hydroxy-2-butanone were found at significantly higher concentrations in the breath of lung cancer patients [7].

Studies also illustrated the usefulness of breath as a biomarker of environmental exposure and dose [8]. Researchers have found that the concentrations of 1,3-butadiene, 2,5-dimethylfuran and benzene were higher in the breath of smokers than non-smokers [9]. Studies on indoor exposure of housewives to chlorinated tap water showed significant correlations between ambient air and breath on trichloromethane, bromodichloromethane, and dichloroacetonitrile [10]. However, no literature has shown studies regarding human exhaled breath as indoor pollution sources.

Though breath studies, particularly those on flavor, may focus more on oral cavity breath, alveolar breath is the preferred indicator of internal conditions. It maximizes diffusion of compounds at the blood breath interface and minimizes contamination from the surroundings, nasal passages, and oral cavity [8]. Breath is typically collected either directly into storage containers (glass tube [11] or Tedlar bags $[7,12])$ or by breath collection apparatus [13], which was an arrangement for the collection, concentration, and optional analysis of VOCs in alveolar breath [14]. When it came to IAQ studies, the study objective should be breath, which includes alveolar breath and dead space breath, instead of alveolar breath alone.

This paper aims to illustrate the rule of human emission of VOCs in the aspect of indoor air quality. In this study, 11 male subjects without smoking habit, 12 female subjects without smoking habit and 12 male subjects with smoking habit were selected. Their samples of exhaled breath were collected and concentrated by sampling bags and sorbent tubes, and analyzed by gas chromatography-mass spectrometry (GC/MS). And for benzene, toluene, xylene and naphthalene, quantitative analysis of were performed, as well as TVOC. The influencing factor of gender and smoking habit would be discussed. 


\section{Method}

\subsection{Subject selection}

35 subjects were selected, could be categorized into three groups: 1. No. 1-11, male, without smoking habit; 2. No. 2-23, female, without smoking habit; 3. No. 24-35, male, with smoking habit. All subjects would fill in a questionnaire about the state of health and living habits.

\subsection{Preliminary subject treatment}

Since two days before the experiment, the subjects should not intake pungent or spicy food. Chilli, onion and garlic were forbidden to take in. Eating was forbidden since the supper the day before the experiment. On the day of the experiment, when brushing the teeth, toothpaste could not be used, only mouthwash with water was allowed.

\subsection{Sample collection and analysis}

Connect a disposable blow nozzle and a sampling bag (Alllabware Scientific, 1L, Figure 1) with a 2-cm long silicone tube to make up sampling apparatus. Before the experiment, the sampling bags should be washed to reduce the residues to a level that as much as it wouldn't affect the results of experiment. Fill the sampling bags with high-purity nitrogen, and then pump it out. This process would be repeated $7-8$ times.
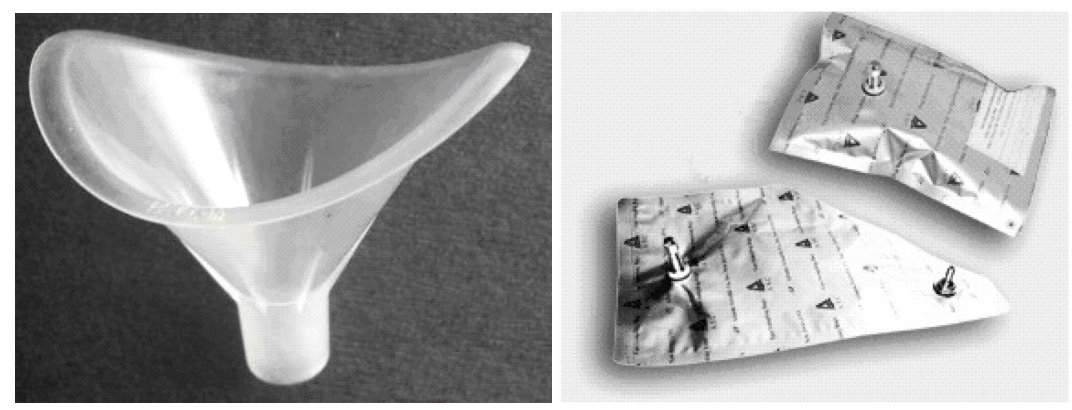

Figure 1: $\quad$ Blow nozzle and sampling bag.

A subject needed to exhale through the disposable blow nozzle into the sampling bag, until the bag was filled with exhaled breath. From 2007.5.9-5.27, 35 subjects were sampled. The sampling locations were the same. The 35 collected sampling bags were brought back to the lab. The air in each bag was taken by a sorbent tube (Tenax), driven by a sampling pump and the flow measured by a flowmeter. Under the flow between $0.68-0.70 \mathrm{~L} / \mathrm{min}$, sampling time $60 \mathrm{~s}$, the exhaled VOCS were concentrated on sorbent tubes. Analysis of 
sorbent tubes was performed by GC-MS (Agilent 6850/5975B) combined with thermal desorption (Markes), for VOC types and concentrations.

\subsection{Quantification}

Select six VOCs and TVOC to quantification: benzene, naphthalene, toluene, m-xylene, p-xylene, o-xylene, respectively. The reason for choosing benzene, toluene, xylene and TVOC is that in the Indoor Air Quality Standard of China (GB/T 18883-2002), their indoor concentrations have provisions of upper limit. Naphthalene was also taken into consideration to represent polycyclic aromatic hydrocarbons (PAHs). Naphthalene is defined as a hazardous air pollutant by the US Environmental Protection Agency (USEPA). If inhaled over a long period of time, naphthalene may cause kidney and liver damage, skin allergy and dermatitis, cataracts and retinal damage, and may attack the central nervous system [19]. For each VOC, five liquid under different concentration were made: $5.5 \mathrm{mg} / \mathrm{L}, 11 \mathrm{mg} / \mathrm{L}, 22 \mathrm{mg} / \mathrm{L}, 44 \mathrm{mg} / \mathrm{L}, 88 \mathrm{mg} / \mathrm{L}$, and each was injected into a sorbent tube, and analyzed by GC-MS. The linear relation between peak area and content could be obtained, and could be used as a standard coefficient in the quantification of the samples.

\section{Results}

\subsection{Kinds of VOCs}

In 35 samples, 156 different substances were detected out. Overall, the kinds of VOCs declined with frequency, which illustrated that breath VOCs were highly individual. The most intensive interval of VOCs detected frequency was 20 $30 \%$. Meanwhile, 12 VOCs had the frequency of $100 \%$, which illustrated the commonness existed besides differences.

Figure 2 is a frequency histogram of detected VOC frequency. The comparison of three groups was shown in Figure 3. Table 1 shows the general exhaled VOCs ranked by detected frequency.

\subsection{Quantification}

The results of the concentrations of naphthalene, benzene, toluene, o-xylene, mxylene, p-xylene and TVOC among different groups were in Figures 4 and 5.

\section{Discussion}

\subsection{Factors analysis}

Use parameters estimation arithmetic on the kinds of VOCs in samples. With the significance level $\alpha=0.05$, compute confidence intervals for the means:

For the three groups, the confidence intervals for the means were: [65.8, 70.7], [69.3, 73.8] and [97.1, 100.8]. The confidence interval of male subjects 


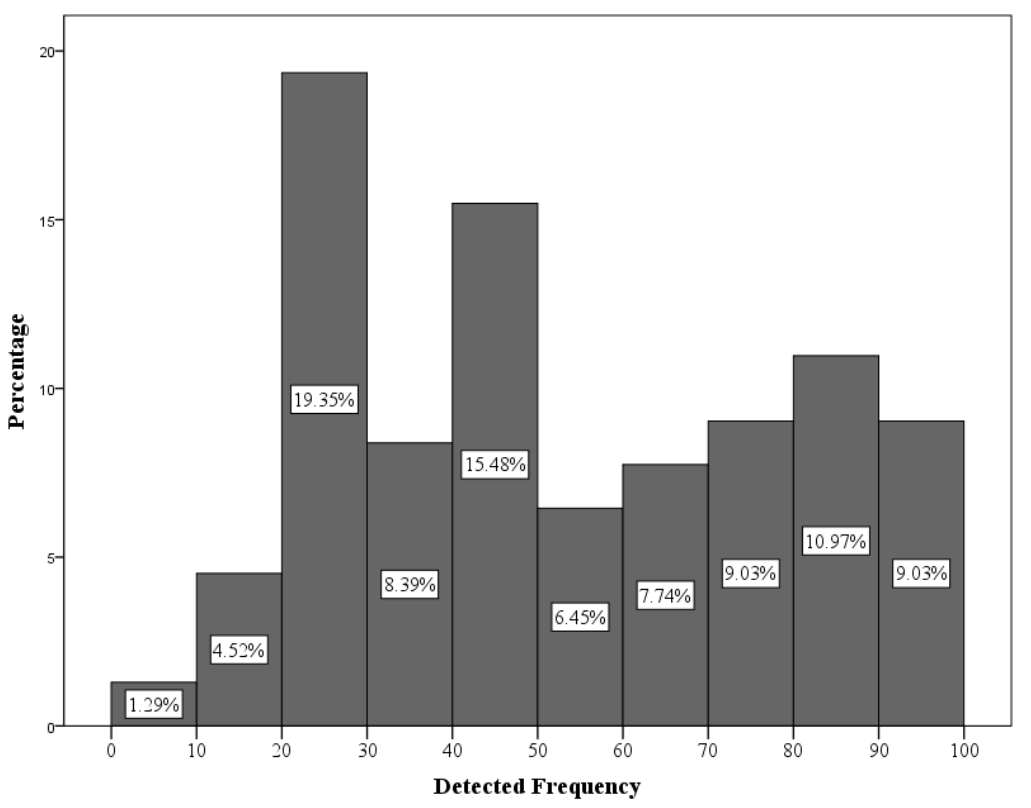

Figure 2: $\quad$ Frequency histogram of detected VOC frequency.

\section{VOC Varieties in Samples}

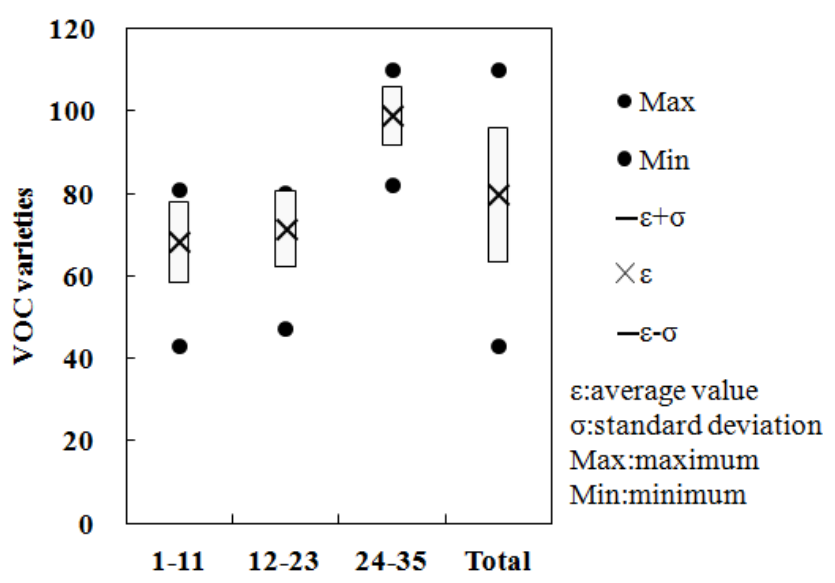

Figure 3: $\quad$ VOC varieties in samples from different groups. 
778 Safety and Security Engineering V

Table 1: $\quad$ Exhaled VOCs ranked by detected frequency $(>80 \%)$.

\begin{tabular}{|c|c|c|c|}
\hline VOC & $\begin{array}{l}\text { Frequency } \\
(\%)\end{array}$ & VOC & $\begin{array}{l}\text { Frequency } \\
(\%)\end{array}$ \\
\hline Acetone & 100 & Pentane, 3-methyl- & 91.29 \\
\hline Benzene & 100 & Heptane & 91.29 \\
\hline $\begin{array}{c}\text { Benzene, 1-ethyl-2- } \\
\text { methyl- }\end{array}$ & 100 & Benzene, 1,3-dimethyl- & 91.29 \\
\hline Benzene, propyl & 100 & p-Xylene & 91.29 \\
\hline Butane, 2-methyl- & 100 & 1-Pentene, 2-methyl- & 88.57 \\
\hline Decane,3,6-dimethyl & 100 & Cyclohexane, ethyl & 88.57 \\
\hline Decane,3,7-dimethyl & 100 & Decane & 88.57 \\
\hline Isoprene & 100 & Ethanone, 1-phenyl & 88.57 \\
\hline Naphthalene & 100 & Nonane & 88.57 \\
\hline $\begin{array}{l}\text { Naphthalene, 1- } \\
\text { methyl- }\end{array}$ & 100 & $\begin{array}{c}\text { Propane, 2-methoxy-2- } \\
\text { methyl- } \\
\end{array}$ & 88.57 \\
\hline Tetradecane & 100 & Ethyl alcohol & 85.71 \\
\hline Toluene & 100 & Ethylbenzene & 82.86 \\
\hline o-Xylene & 97.14 & Hexane, 3-methyl- & 82.86 \\
\hline Heptane, 2-methyl- & 97.14 & Styrene & 82.86 \\
\hline Hexane & 97.14 & Tridecane & 82.86 \\
\hline Pentodecane & 97.14 & 4,4-Dimethyloctane & 80 \\
\hline Benzene, ethyl & 94.29 & a-Pinene, & 80 \\
\hline Dodecane & 94.29 & $\begin{array}{c}\text { Benzene, } 1,2,3,5- \\
\text { tetramethyl- } \\
\end{array}$ & 80 \\
\hline Heptane, 3-methyl- & 94.29 & $\begin{array}{c}\text { Benzene,1-methyl-4- } \\
\text { (1-methylethyl)- }\end{array}$ & 80 \\
\hline $\begin{array}{c}\text { Pentane, } 2,3,4- \\
\text { trimethyl- }\end{array}$ & 94.29 & Benzothiazole & 80 \\
\hline Pentane, 2-methyl- & 94.29 & Undecane,4-methyl- & 80 \\
\hline Cyclohexane, methyl & 91.29 & & \\
\hline
\end{tabular}




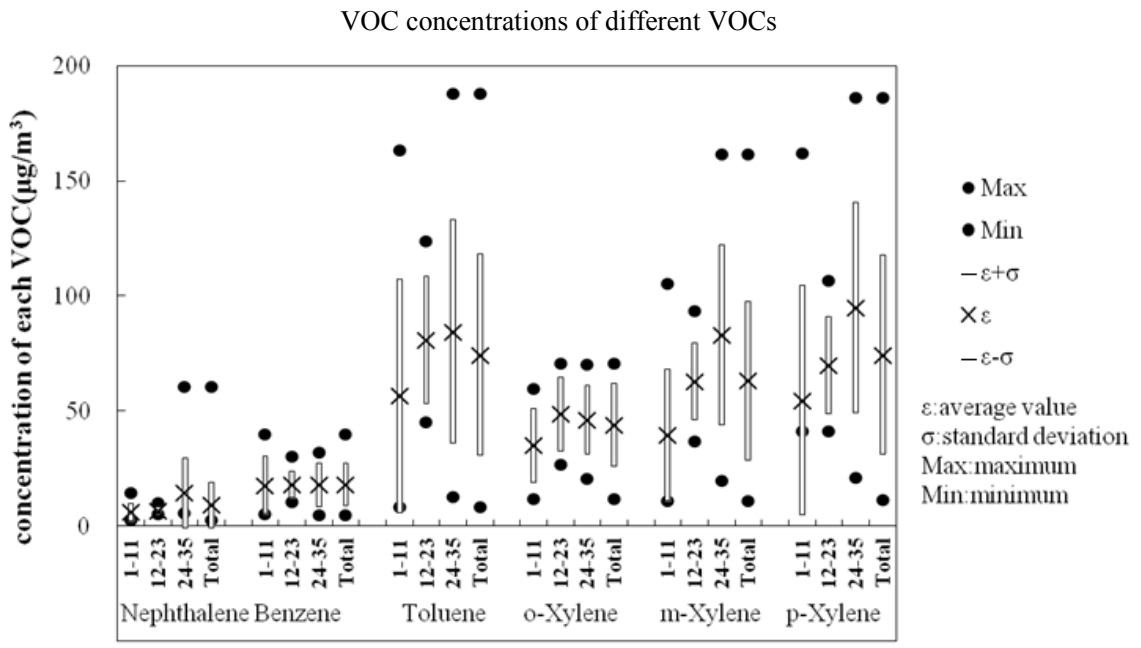

Figure 4: VOC concentrations of naphthalene, benzene, toluene, and xylenes.

TVOC concentrations in samples

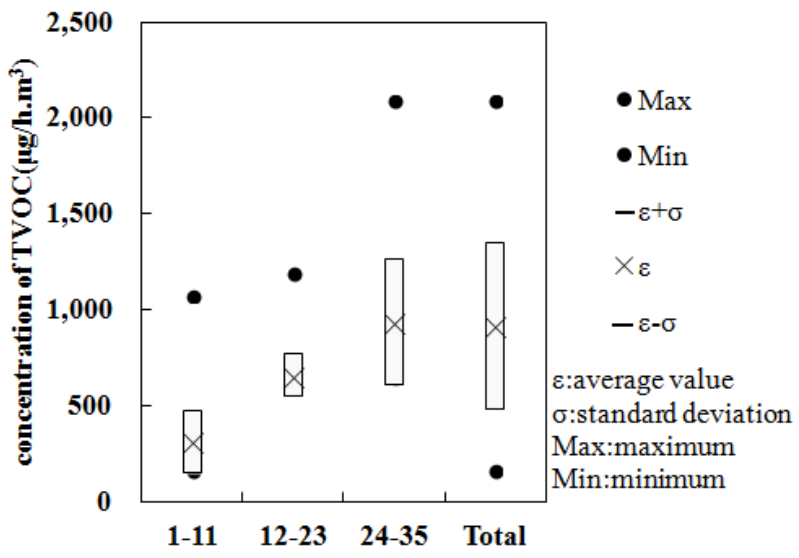

Figure 5: Concentrations of TVOC.

without a smoking habit and female subjects without a smoking habit overlapped, which indicated the not significantly differences between male and female. The confidence interval of male subjects without a smoking habit and male subjects with a smoking habit didn't overlap, which indicated the significantly differences between non-smokers and smokers. To insure the validity of this conclusion, a method of relative frequency was used to find the incremental substances in exhaled breath of smokers. For a certain VOC, compute the frequency of smokers dividing the frequency of all the subjects, if the relative frequency was more than $200 \%$, this substance would be considered 
as the target substance. 15 VOCs were found to be possible incremental substances in exhaled breath of smokers, mainly composed of ketones and alkenes (as shown in Table 2).

The data of concentrations of different VOCs were analyzed by normal distribution and t-test. The results of t-test are shown in Table 3. Concentration

Table 2: $\quad 15$ VOCs that had a relative frequency larger than $200 \%$ and were considered as the incremental substances in exhaled breath of smokers.

\begin{tabular}{|c|c|c|c|}
\hline VOC & $\begin{array}{c}\text { Relative } \\
\text { Frequency } \\
(\%)\end{array}$ & VOC & $\begin{array}{c}\text { Relative } \\
\text { Frequency } \\
(\%)\end{array}$ \\
\hline 1-Butene, 3-methyl & 291.7 & Pyridine,4-methyl- & 291.7 \\
\hline 2-Butanone & 291.7 & 1,3,5-Hexatriene,(z)- & 291.7 \\
\hline Furan,2,5-dimethyl & 291.7 & 3-Pentanone & 259.3 \\
\hline Methyl Isobutyl Ketone & 291.7 & 2-Pentene,3-methyl,(z)- & 255.2 \\
\hline 2,3-Butanedione & 291.7 & $\begin{array}{c}\text { 1,3-Cyclopentadiene,1- } \\
\text { methyl- }\end{array}$ & 226.9 \\
\hline 3-Penten-1_yne,(e) & 291.7 & Cyclohexanone & 218.8 \\
\hline 3-Penten-2-one,(e) & 291.7 & $\begin{array}{c}\text { 1,2-Benzenedicarboxylic } \\
\text { acid,ditthyl ester }\end{array}$ & 205.8 \\
\hline Pyridine, & 291.7 & & \\
\hline
\end{tabular}

Table 3: T-test on different factors affecting the concentrations of different VOCs.

\begin{tabular}{|c|c|c|c|c|}
\hline No. & $\begin{array}{c}\text { Comparison } \\
\text { factor }\end{array}$ & VOC & $\begin{array}{c}\text { Concentration } \\
\text { difference }\left(\mu \mathrm{g} / \mathrm{m}^{3}\right)\end{array}$ & $\mathrm{p}$ \\
\hline 1 & Gender & Naphthalene & -0.49 & 0.611 \\
\hline 2 & Smoking & Naphthalene & -8.72 & 0.118 \\
\hline 3 & Gender & Benzene & -0.86 & 0.770 \\
\hline 4 & Smoking & Benzene & -0.23 & 0.962 \\
\hline 5 & Gender & Toluene & -27.55 & 0.105 \\
\hline 6 & Smoking & Toluene & -28.40 & 0.311 \\
\hline 7 & Gender & o-Xylene & -17.72 & 0.021 \\
\hline 8 & Smoking & o-Xylene & -15.53 & 0.034 \\
\hline 9 & Gender & m-Xylene & -17.94 & 0.161 \\
\hline 10 & Smoking & m-Xylene & -46.57 & 0.029 \\
\hline 11 & Gender & p-Xylene & -10.00 & 0.654 \\
\hline 12 & Smoking & p-Xylene & -44.43 & 0.109 \\
\hline 13 & Gender & TVOC & -418.07 & 0.001 \\
\hline 14 & Smoking & TVOC & -727.91 & 0.001 \\
\hline
\end{tabular}


difference means the concentration of the VOC of Group 2 (Gender) or 3 (Smoking) subtracting Group 1.

The concentrations of these kinds of VOCs were higher in female subjects' breath than in male subjects' breath under the non-smoking circumstances. With the significance level $\alpha=0.05$, the difference was significant $(\mathrm{P}<0.05)$ in the case of TVOC (gender and smoking both), o-xylene (gender and smoking both) and m-xylene (smoking only). For naphthalene, m-xylene, p-xylene and TVOC, the factor of smoking played a more important role than the factor of gender. For benzene, toluene and o-xylene, the factor of gender was less visibly stronger.

\subsection{Emission rate and comparison with building materials}

Tidal volume (VT) is the lung volume representing the normal volume of air displaced between normal inspiration and expiration when extra effort is not applied [20]. Total minute ventilation (VE) is the product of VT and frequency (f) $[21,22]$. Through calculation and comparison, the average VE of male subjects without smoking habit, female subjects without smoking habit and male subjects with smoking habit were 7.30, 5.89 and 7.22, respectively. The standard deviations were $0.22,0.14$ and 0.19 , respectively. The VE of female subjects was significantly less than male subjects $(\Delta=1.41, \mathrm{P}<0.001)$. The VE difference between male subjects with and without smoking habit can be ignored. Emission rates of VOCs from breath could be obtained if we multiply exhaled VOC concentrations with VE.

To show that the emission of VOCs from humans' breath had impact on indoor air quality, two common materials, carpet and particle board, were selected for reference.

The change graphs of the TVOC emission rate per area from carpet and particle board are in Figures 12 and 13, respectively. The initial and average emission rate per area of TVOC from carpet were $152 \mu \mathrm{g} / \mathrm{m}^{2} \cdot \mathrm{h}$ and $92.67 \mu \mathrm{g} / \mathrm{m}^{2} \bullet \mathrm{h}$, respectively. The initial and average emission rate per area of TVOC from particle board were $56004 \mu \mathrm{g} / \mathrm{m}^{2} \cdot \mathrm{h}$ and $2242 \mu \mathrm{g} / \mathrm{m}^{2} \cdot \mathrm{h}$, respectively.

Table 4 showed the equivalent material areas as a human's breath, using average emission rate of TVOC from human breath compared with initial emission rate and average emission rate of TVOC from materials, respectively.

\subsection{Limitations}

The sampling location was a grove in the campus, where the concentrations of VOCs were low. The background VOCs were out of consideration, which may cause experimental errors, and add uncontainable substances into exhaled breath to interfere experimental results.

Experiments related to humans could be influenced by many factors, most of which were uncontrollable. Meanwhile, there were interactions between factors. For example, the factor of smoking habit had strong correlation with the factor of age and the factor of drinking habit, which may also cause the increase in the kinds and concentrations of VOCs. All of the above made it hard to extract univariate analyses results to determine any associations between variables and 
Table 4: Different materials' area that equivalent to a human's exhaled TVOC, using Initial emission rate and average emission rate, respectively.

\begin{tabular}{|c|c|c|c|c|}
\hline \multirow{2}{*}{$\begin{array}{c}\text { Sample } \\
\text { No. }\end{array}$} & \multicolumn{2}{|c|}{ Carpet $\left(\mathrm{m}^{2}\right)$} & \multicolumn{2}{c|}{ Particle board $\left(\mathrm{m}^{2}\right)$} \\
\cline { 2 - 5 } & $\begin{array}{c}\text { Initial } \\
\text { emission rate } \\
\text { for reference }\end{array}$ & $\begin{array}{c}\text { Average } \\
\text { emission rate } \\
\text { for reference }\end{array}$ & $\begin{array}{c}\text { Initial } \\
\text { emission rate } \\
\text { for reference }\end{array}$ & $\begin{array}{c}\text { Average } \\
\text { emission rate } \\
\text { for reference }\end{array}$ \\
\hline $1-11$ & 0.621 & 1.019 & 0.002 & 0.042 \\
\hline $12-23$ & 1.299 & 2.131 & 0.004 & 0.088 \\
\hline $24-35$ & 1.849 & 3.032 & 0.005 & 0.125 \\
\hline Total & 1.807 & 2.965 & 0.005 & 0.123 \\
\hline
\end{tabular}

outcomes, in the case of unknown laws. To expand the number of samples, make the factors controllable, and set up a model which may reveal the phenomenon mechanically, further studies are required in these directions.

\section{Conclusion}

In this study, exhaled breath was studied as sources of indoor air pollution. 11 male subjects without smoking habit, 12 female subjects without smoking habit and 12 male subjects with smoking habit were selected. By gathering their samples of exhaled breath, using gas chromatography-mass spectrometry (GC/MS), and conclusions were obtained as follows:

1) 135 VOCs were observed in total. An average breath sample contained 79.7 VOCs (SD16.2, range 43-110) were obtained, which was highly individual.

2) 12 VOCs were observed in all 35 subjects, which indicated that breathing VOCs had concordances among humans to an extent.

3) Exhaled VOCs of smoking subjects were more diverse and of higher concentration of some VOCs. Increased varieties were mainly ketones and alkenes.

4) Exhaled VOCs of female subjects were not more diverse but of higher concentration and higher emission rate of some VOCs, in spite of less breath volume than male subjects.

5) Use average emission rate of TVOC in 7 days for reference, a male nonsmoker amounted to about $2.440 \mathrm{~m}^{2}$ carpet or $0.101 \mathrm{~m}^{2}$ particle board. A male smoker amounted to about $6.018 \mathrm{~m}^{2}$ carpet or $0.249 \mathrm{~m}^{2}$ particle board. So there seems to be a significant necessity to take human breath emission of VOCs into consideration in dense environment.

\section{References}

[1] Spengler, J.D. and K. Sexton, Indoor air-pollution - a public-health perspective. Science, 1983, 221(4605): p. 9-17. 
[2] Bradford O. Brooks, W.F.D., Understanding indoor air quality. 1992: Boca Raton: CRC Press. 22.

[3] De Bellie, L.H.F.A., Review of the effect of environmental parameters on material proemissions, in Proceedings of the 2nd International Conference on Indoor Air Quality, Ventilation, and Energy Conservation in Buildings, 1995: Montreal, Canada.

[4] Fanger, P.O., Introduction of the olf and the decipol units to quantify airpollution perceived by humans indoors and outdoors. Energy and buildings, 1988, 12(1): p. 1-6.

[5] Phillips, M., et al., Variation in volatile organic compounds in the breath of normal humans. Journal of Chromatography B, 1999, 729(1-2): p. 7588.

[6] Van den Velde, S., et al., GC-MS analysis of breath odor compounds in liver patients. Journal of Chromatography B-analytical Technologies in the Biomedical and Life Sciences, 2008, 875(2): p. 344-348.

[7] Song, G., et al., Quantitative breath analysis of volatile organic compounds of lung cancer patients. Lung Cancer, 2010, 67(2): p. 227231.

[8] Vereb, H., et al., The Possibilities Will Take Your Breath Away: Breath Analysis for Assessing Environmental Exposure. Environmental Science \& Technology, 2011, 45(19): p. 8167-8175.

[9] Perbellini, L., et al., Comparison of breath, blood and urine concentrations in the biomonitoring of environmental exposure to 1,3-butadiene, 2,5dimethylfuran, and benzene. International Archives of Occupational and Environmental Health, 2003, 76(6): p. 461-466.

[10] Kim, H., Seasonal variations in the household exposures of Korean housewives to volatile tap water disinfection by-products. Science of the Total Environment, 2008, 403(1-3): p. 59-67.

[11] Schreiber, J.S., et al., Apartment residents' and day care workers' exposures to tetrachloroethylene and deficits in visual contrast sensitivity. Environmental Health Perspectives, 2002, 110(7): p. 655-664.

[12] Schwarz, K., et al., Breath acetone-aspects of normal physiology related to age and gender as determined in a PTR-MS study. Journal of Breath Research, 2009, 3(0270032).

[13] Phillips, M., et al., Variation in volatile organic compounds in the breath of normal humans. Journal of Chromatography B, 1999, 729(1-2): p. 7588.

[14] Phillips, M., Breath collection apparatus, 2001. 